\title{
Wage returns to mid-career investments in job training through employer supported course enrollment: evidence for Canada
}

\author{
Wen $\mathrm{Ci}^{1+}$, Jose Galdo ${ }^{2 \dagger}$, Marcel Voia ${ }^{1 \dagger}$ and Christopher Worswick ${ }^{1 *+}$
}

\author{
* Correspondence: \\ christopher.worswick@carleton.ca \\ ${ }^{\dagger}$ Equal contributors \\ ${ }^{1}$ Department of Economics, \\ Carleton University, 1125 Colonel By \\ Drive, Ottawa, ON K1S 5B6, Canada \\ Full list of author information is \\ available at the end of the article
}

\begin{abstract}
Using longitudinal data for Canada, we analyze the incidence and wage returns to employer supported course enrollment for men and women. Availability of confidential data, along with a relatively rich set of observable covariates, lead us to the estimation of difference-in-differences matching models of the effect of employer supported course enrolment on wages. The estimated average treatment effects on the treated range from 5.5 to 7.2 percent for men and 7.1 to 9.0 for women. While high-skilled workers show disproportionately higher rates of participation in employer-supported training, we observe no wage premiums for these types of workers. Statistically significant positive wage returns are found, on the other hand, for low-skilled workers.

JEL codes: C14, 120, J24, J31, M53

Keywords: Return to adult training; Employer supported course enrollment; Difference-in-differences models; Propensity score matching
\end{abstract}

\section{Introduction}

Lifelong learning, such as adult education and training, has become a relevant practice because of technological changes in production processes, job mobility across industries and occupations, and workers' lack of proper skills and competences. Heckman et al. (1998) estimated that over half of lifetime human capital is obtained through lifelong investments, including training within firms. Our focus is on the incidence and returns to adult (age 25 and older) employer-supported training for women and men in Canada. Using longitudinal data from the confidential versions of the Survey of Labour and Income Dynamics (SLID) of Statistics Canada, we analyze the impact on wage outcomes of mid-career investments in job-related training. We exploit the availability of a rich, relevant set of socio-demographic and labor-market characteristics for a large set of workers to implement semiparametric difference-in-differences matching models. Unlike the extensive literature on returns to formal schooling, relatively few studies have addressed the returns to training programs among adult learners in Canada.

Results shows positive and statistically significant wage returns to mid-career investments in training in the Canadian labor market, ranging in size from 5 to 9 percent for both men and women. These estimated wage premiums are steady across several 
sensitivity analyses including changes in (1) the estimation sample, (2) matching estimator, (3) bandwidth parameters and (4) empirical common support. Relative to the evidence reported for employer-supported training in the U.S. (see the review in Carneiro and Heckman 2003), our findings are in the lower range of the point estimates.

Contrary to the findings of previous studies that used earlier panels of the SLID data in Canada (e.g., Zhang and Palameta 2006), we generally find equal or higher wage premiums for women than that for men. Although the magnitude of the gender differences are somewhat sensitive to changes in the estimation sample and econometric details, we do not find statistically significant wage advantages for men relative to women. This result suggests that women are not only making gains in terms of labor market participation and wage rates in Canada in recent years but they are also benefiting to the same extent as, or slightly even more than, men when participating in employersupported adult training.

The analysis of the determinants of employer-supported training participation is quite consistent with previous findings reported for Canada and the U.S. White, high-skilled individuals who hold longer tenure jobs in large firms are more likely to participate in employer-supported training relative to non-white, low-skilled individuals who hold shorter tenure jobs in smaller firms. Among all variables used in the specification of the propensity scores model, levels of education show the largest marginal effects in term of training participation. For instance, a woman with a bachelor degree has a 25 percentage point higher probability of training participation relative to a woman with less than high school education. Yet, we observe no wage effects for high-skilled workers. On the contrary, participation in employer-supported training yields positive and statistically significant wage premiums only for low-skilled workers. This result suggests that firms might benefit more if they reallocate adult training investments towards the least educated workers.

Given that our empirical approach is based on differences in outcomes between treated and untreated individuals before and after participation, one common concern for the internal validity of the estimated wage premiums is the underlying assumption of 'parallel trends' for the (counterfactual) outcomes. We assess indirectly this concern by exploiting the longitudinal nature of the SLID panel data. Most importantly, we do not find evidence of an 'Ashenfelter's Dip' in our data.

\section{Assessment of the adult training literature in Canada}

The literature on employer-supported adult training, a particular form of lifelong learning, is relatively new in Canada and the result of the availability of new micro level data. It is well documented that the overall participation in adult education and training has consistently increased in the last decade in Canada, reaching up to 30 percent of individuals aged 25 to $64^{1}$. Yet, in contrast to the extensive literature on returns to formal schooling, relatively few studies have addressed the returns to training programs among adult learners in Canada, and as a result, evidence on their effectiveness is relatively thin, generated mostly in recent years and, with few exceptions, confined to government reports ${ }^{2}$.

Evidence on returns to training programs among adult learners in Canada are mainly based on three sources of micro-level survey data: (1) the Adult Education and 
Training Program (AETS), a complement to the Labour Force Survey (LFS), and as result includes all of the LFS information on labor markets and demographic characteristics; (2) the Survey of Labour and Income Dynamics (SLID), a longitudinal household survey that follows the same sample of adults for six consecutive years on a wide variety of labor-market and socio-economic matters; and (3) the Workplace and Employer Survey (WES), a longitudinal matched data on employers and their employees. Table 1 (below) reports a representative selection of adult training studies in Canada. A welldefined pattern is the heterogeneity in the definition of "training" that varies in terms of content, scope, funding, and intensity across studies. This is indeed driven by how adult education and training is measured in the surveys. While the WES survey provides information for on-the-job and classroom employer-supported training programs, the AETS survey distinguishes training "programs" from training "courses", with the former leading to formal certification and the latter not. This survey also makes a distinction between employer-supported and government-supported training programs. The SLID survey makes a distinction between training "programs" provided by educational institutions and conducive to formal certification, and training "courses" such as job-related seminars, courses workshops, and conferences. Starting in 2002, additional questions were added in the SLID survey that allows one to know whether employers provided or paid for the training ${ }^{3}$.

Independently of the particular definition of training used by these studies, the evidence shows positive and significant overall effects of training on measures of wages (ranging from $1 \%$ to $17 \%$ ) and productivity (ranging from 3\% to 36\%). The magnitude of the impacts is, however, dependent on the data structure, econometric approach, outcomes of interest, and the specific definition of "training." Indeed, several features emerge from this analysis. First, parametric models that exploit longitudinal data structure show smaller effects than studies that are based on cross-sectional approaches. For instance, Dostie and Leger (2014) report 3.5\% and 0.6\% gains on weekly wages for classroom employer-supported training when implementing OLS and fixed-effects models. One strong conclusion of this literature review is that cross-sectional ordinary least squares (OLS) returns to adult training are biased upward.

Second, econometric models that control for unobserved heterogeneity and endogeneity of training decisions report positive but smaller effects than standard parametric models. In this regard, Parent (2003), for instance, shows almost 50\% reductions, from $7.4 \%$ to $3.4 \%$, in the magnitude of the productivity impacts when comparing the results from parametric fixed-effect models and panel GMM models. Similarly, Hui and Smith (2001) show that cross-sectional matching methods reduce consistently the magnitude of the estimated effects with respect to traditional parametric selection models in the context of the AETS data. For weekly earnings, the authors report matching average impacts of $\$ 30$ dollars, while parametric selection models yield effects of \$407 dollars. Indeed, Hui and Smith (2001) find unreliable estimates for several widely used parametric estimators, which lead them to conclude that the primary problem with the estimates lies in the data rather than in the estimates.

Third, training impacts are very pronounced for productivity, measured as value added by worker, relative to hourly or weekly wages. In this regard, Dostie (2013) and Dostie and Leger (2014) show large productivity gains, ranging from $3.4 \%$ to $36 \%$, for firm-supported training. Some other outcomes of interest are also reported in this 
Table 1 Literature review of adult education and training in Canada

\begin{tabular}{|c|c|c|c|c|c|c|}
\hline Author & $\begin{array}{l}\text { Data } \\
\text { source }\end{array}$ & $\begin{array}{l}\text { Age } \\
\text { group }\end{array}$ & Estimator & $\begin{array}{l}\text { Type of } \\
\text { training }\end{array}$ & Outcomes & Findings \\
\hline \multirow[t]{2}{*}{$\begin{array}{l}\text { Zhang } \\
\text { and } \\
\text { Palameta } \\
\text { (2006) }\end{array}$} & $\begin{array}{l}1998-2002 \\
\text { SLID }\end{array}$ & $17-59$ & $\begin{array}{l}\text { Parametric } \\
\text { multivariate } \\
\text { models }\end{array}$ & Any training & $\begin{array}{l}\text { Hourly and } \\
\text { annual wage } \\
\text { earnings }\end{array}$ & $\begin{array}{l}7.7 \% \text { and } 6.8 \% \text { gain in } \\
\text { hourly and annual } \\
\text { wages for men, not } \\
\text { significant impacts for } \\
\text { women. }\end{array}$ \\
\hline & & & & & & $\begin{array}{l}3 \% \text { gain in annual } \\
\text { wages for both men } \\
\text { and women for both } \\
\text { types of training; }\end{array}$ \\
\hline $\begin{array}{l}\text { Drewes } \\
\text { (2008) }\end{array}$ & $\begin{array}{l}\text { 2002-2004 } \\
\text { SLID }\end{array}$ & $25-64$ & $\begin{array}{l}\text { random- } \\
\text { effects } \\
\text { parametric } \\
\text { multivariate } \\
\text { analysis }\end{array}$ & $\begin{array}{l}\text { distinction } \\
\text { between } \\
\text { training } \\
\text { programs } \\
\text { and training } \\
\text { courses }\end{array}$ & $\begin{array}{l}\text { annual growth } \\
\text { earnings, prob. of } \\
\text { unemployment }\end{array}$ & $\begin{array}{l}2.3 \% \text { fall in } \\
\text { unemployment for } \\
\text { training courses only. }\end{array}$ \\
\hline $\begin{array}{l}\text { Hui and } \\
\text { Smith } \\
\text { (2001) }\end{array}$ & 1998 AETS & $25-64$ & $\begin{array}{l}\text { nearest- } \\
\text { neigbor } \\
\text { matching and } \\
\text { parametric } \\
\text { selection } \\
\text { models }\end{array}$ & $\begin{array}{l}\text { employer- } \\
\text { financed, } \\
\text { government- } \\
\text { financed and } \\
\text { self-financed } \\
\text { training }\end{array}$ & $\begin{array}{l}\text { weekly earnings } \\
\text { and employment }\end{array}$ & $\begin{array}{l}\$ 30 \text { for weekly earnings } \\
\text { and } 2.6 \% \text { for } \\
\text { employment for both } \\
\text { men and women. } \\
\text { Positive and significant } \\
\text { effects for employer- } \\
\text { supported training, } \\
\text { negative effects for } \\
\text { government-sponsored } \\
\text { training for both men } \\
\text { and women. }\end{array}$ \\
\hline $\begin{array}{l}\text { Myers } \\
\text { and } \\
\text { Myles } \\
(2005)\end{array}$ & $\begin{array}{l}2004 \\
\text { WALL } \\
\text { (and 2008 } \\
\text { AETS) }\end{array}$ & $25-55$ & $\begin{array}{l}\text { logistic } \\
\text { regression } \\
\text { models }\end{array}$ & $\begin{array}{l}\text { any formal } \\
\text { training or } \\
\text { education for } \\
\text { adult workers }\end{array}$ & $\begin{array}{l}\text { self-reported } \\
\text { wage gains and } \\
\text { promotion }\end{array}$ & $\begin{array}{l}53 \% \text { and } 44 \% \text { of low- } \\
\text { and high-skill workers } \\
\text { report having an } \\
\text { increases in wages and } \\
37 \% \text { and } 33 \% \text { report } \\
\text { having a promotion }\end{array}$ \\
\hline $\begin{array}{l}\text { Parent } \\
(2003)\end{array}$ & $\begin{array}{l}\text { 1991-95 } \\
\text { School } \\
\text { Leavers } \\
\text { Survey }\end{array}$ & $18-20$ & $\begin{array}{l}\text { OLS and } \\
\text { fixed-effects } \\
\text { regression } \\
\text { models }\end{array}$ & $\begin{array}{l}\text { any employer- } \\
\text { supported } \\
\text { training } \\
\text { program or } \\
\text { course }\end{array}$ & $\begin{array}{l}\text { weekly and } \\
\text { hourly wages; } \\
\text { mobility }\end{array}$ & $\begin{array}{l}13 \%-17 \% \text { for men for } \\
\text { weekly and hourly } \\
\text { wages. For women, } \\
5 \%-12 \% \text { and } 1-8 \% \text { for } \\
\text { weekly and hourly } \\
\text { wages. }\end{array}$ \\
\hline $\begin{array}{l}\text { Dostie } \\
\text { (2013) }\end{array}$ & $\begin{array}{l}1999-2006 \\
\text { WES }\end{array}$ & NA & $\begin{array}{l}\text { panel GMM } \\
\text { and fixed-effects } \\
\text { parametric } \\
\text { models }\end{array}$ & $\begin{array}{l}\text { on-the-job } \\
\text { and classroom } \\
\text { employer- } \\
\text { supported } \\
\text { training } \\
\text { programs }\end{array}$ & productivity & $\begin{array}{l}7.4 \% \text { and } 3.4 \% \text { increase } \\
\text { in productity using FE } \\
\text { and GMM for classroom } \\
\text { training. No impacts for } \\
\text { OJT }\end{array}$ \\
\hline $\begin{array}{l}\text { Dostie } \\
\text { and } \\
\text { Leger } \\
\text { (2014) }\end{array}$ & $\begin{array}{l}\text { 1999-2006 } \\
\text { WES }\end{array}$ & $35-64$ & $\begin{array}{l}\text { fixed-effects } \\
\text { and two-factor } \\
\text { analysis of } \\
\text { covariance }\end{array}$ & $\begin{array}{l}\text { clasroom } \\
\text { employer- } \\
\text { supported } \\
\text { training } \\
\text { programs }\end{array}$ & $\begin{array}{l}\text { weekly wages } \\
\text { and productivity }\end{array}$ & $\begin{array}{l}3.5 \% \text { and } 1 \% \text { in the FE } \\
\text { and mixed model for } \\
\text { weekly wages. Large } \\
\text { productivity gains ( } 36 \% \text {, } \\
21 \% \text { and } 4 \% \text { for workers } \\
\text { younger than } 35,35-44, \\
\text { and above } 55, \\
\text { respectively) }\end{array}$ \\
\hline $\begin{array}{l}\text { Yoshida } \\
\text { and } \\
\text { Smith } \\
\text { (2005) }\end{array}$ & $\begin{array}{l}1999-2000 \\
\text { WES }\end{array}$ & NA & $\begin{array}{l}\text { cross-sectional } \\
\text { and wage } \\
\text { growth } \\
\text { parametric OLS } \\
\text { models }\end{array}$ & $\begin{array}{l}\text { on-the-job } \\
\text { and classroom } \\
\text { employer- } \\
\text { supported } \\
\text { training } \\
\text { programs }\end{array}$ & $\begin{array}{l}\text { hourly wages of } \\
\text { immigrants }\end{array}$ & $\begin{array}{l}\text { no differential impacts } \\
\text { between immigrants } \\
\text { and native-born whites, } \\
\text { yet some differential } \\
\text { impacts in favor of } \\
\text { immigrants when } \\
\text { computing growth } \\
\text { wage models. No clear } \\
\text { results by type of } \\
\text { training. }\end{array}$ \\
\hline
\end{tabular}


Table 1 Literature review of adult education and training in Canada (Continued)

\begin{tabular}{|c|c|c|c|c|c|c|}
\hline $\begin{array}{l}\text { Drolet } \\
(2002)\end{array}$ & $\begin{array}{l}1999-2000 \\
\text { WES }\end{array}$ & NA & $\begin{array}{l}\text { cross-sectional } \\
\text { OLS models }\end{array}$ & $\begin{array}{l}\text { training } \\
\text { intensity }\end{array}$ & hourly wages & $\begin{array}{l}\text { training expenditures } \\
\text { has a significant impact } \\
\text { on men but not women }\end{array}$ \\
\hline $\begin{array}{l}\text { Havet } \\
(2006)\end{array}$ & $\begin{array}{l}1999-2000 \\
\text { WES }\end{array}$ & NA & $\begin{array}{l}\text { parametric } \\
\text { selection model }\end{array}$ & $\begin{array}{l}\text { on-the-job } \\
\text { and classroom } \\
\text { employer- } \\
\text { supported } \\
\text { training } \\
\text { programs }\end{array}$ & $\begin{array}{l}\text { hourly wages, } \\
\text { promotion }\end{array}$ & $\begin{array}{l}\text { positive impacts on } \\
\text { wage for women but } \\
\text { not for men regardless } \\
\text { the type of training; } \\
\text { positive impact on } \\
\text { promotion only for OJT } \\
\text { but not classroom } \\
\text { training }\end{array}$ \\
\hline
\end{tabular}

literature (e.g., employment, promotion, mobility). Myers and Myles (2005) and Havet (2006), for instance, report positive and large training effects for the promotion variable. It is difficult, however, to draw overall patterns for other outcome variables due to the lack of outcome commonality across studies.

Fourth, important heterogeneity in training impacts emerges when considering the particular types of training programs. In general, one can observe that employersupported classroom training yields higher returns relative to employer-supported onthe-job training, particularly when the outcome of interest is productivity (e.g., Turcotte and Rennison 2004, Dostie 2013). For wage outcomes, the evidence is more inconclusive. Moreover, although there are not many studies that directly address the distinction between employer-sponsored and government-sponsored programs, the evidence suggests that the former yields positive and significant effects, while one observes zero or negative effects for the latter for both wages and employment (Hui and Smith 2001). This result is consistent with observed patterns in developed economies. While it is widely reported that subsequent labor-market earnings of trainees increase for participants in employer-supported training programs (see Barron et al. 1997, Blundell et al. 1999, and Frazis and Loewenstein 2005, Lillard and Tan 1992, and Almeida and Carneiro 2009), participants in government-training program show modest or no wage benefits (see Heckman et al. 1999 and Card et al. 2010 surveys).

Fifth, this literature shows higher returns to adult training for men relative to women (e.g., Parent 2003 and Hui and Smith 2001, Zhang and Palameta 2006), although the evidence is far from conclusive as the wage differences by gender are modest and dependent on the training measure. For example, while Drolet (2002) reported positive impacts on the wages of men (but not women) for measures of intensity of training, Havet (2006) reports statistically significant results for women (but not for men) for measures of incidence of training. Finally, and given that our research design is based on the SLID data, it is important to notice in Table 1 that there are only two government reports by Zhang and Palameta (2006) and Drewes (2008) that employed this dataset to address wage returns to adult education and training in Canada. The former used two complete but early panels, from 1993-1998 and 1996-2001, while the latter used a more restricted period of analysis, 2002-2004 data. The picture that emerges from these government reports suggests that formal adult education and training in Canada has positive and statistically significant returns, ranging between 3 and 10 percent.

In this study, we present analysis complementary to but different from previous studies that analyzed wage returns to adult education and training programs in Canada. First, our 
study focuses on a particular type of adult education, employer-supported course enrollment, which has received attention only in recent years in Canada. Second, our analysis is based on more up-to-date information as it uses the confidential versions of the 20022007 and 2005-2009 SLID panel datasets. Beginning in 2002, a richer set of information on formal education and training activities undertaken by adult workers and sponsored by firms were included. Third, the main independent variable of interest is measured both at the extensive (training participation) and intensive (number of hours) margins. Fourth, the empirical analysis is based mainly on semiparametric difference-in-differences matching models; this approach has the advantage of relaxing functional form assumptions in the outcome equation and controlling for time-invariant unobserved variables. A detailed discussion about potential problems with the functional form specifications of linear models in the context of training programs can be found in Frazis and Loewenstein (2005). In addition, the implementation of semiparametric matching methods allows us to compare more comparable samples and, thus, control for additional sources of bias related to common support issues in the data. To the best of our knowledge, Hui and Smith (2001) is the only study that implements semiparametric matching methods in the estimation of average treatment effects for adult training in Canada. Finally, given the importance of workers' skills in the Canadian labor market, this study analyzes the benefits of adult training by skills status with a focus on less skilled workers.

\section{Data sources}

The Survey of Labour and Income Dynamics (SLID) is a longitudinal, nationally representative household survey collected by Statistics Canada that follows the same sample of adults for six consecutive years on a wide variety of labor-market and socioeconomic variables. We use the confidential files of the two most recent SLID panels panel 4 (2002-2007) and panel 5 (2005-2010) accessed through the Carleton-OttawaOutaouais Local Research Data Centre in Ottawa. Respondents in panel 4 are tracked for all six years (2002 to 2007), while respondents in panel 5 are only tracked from 2005 to 2009 due to the absence of the variable of the employer-supported course enrolment in 2009 and 2010 of panel 5. Unlike the earlier panels, these contain the most detailed information related to employer support of training and education. The sample is restricted to individuals age 25 to 55 . The lower bound for age is chosen in order to restrict attention to individuals who are likely to have completed their initially 'planned' schooling and entered the labor market for the first time. The upper age restriction is chosen to abstract from retirement ages. This is especially important given our interest in understanding the impact of educational investments on post-training wage outcomes. In each part of the analysis, we employed the SLID longitudinal weights, which are designed to generate estimates that are representative of the population of Canada's 10 provinces at the time the longitudinal sample was selected. They are equal to the households' inverse selection probability ${ }^{4}$.

In the context of the SLID panel data, employer-supported adult training is defined as enrollment into any job-related 'training program' or 'training course' that is offered by or paid for by the employer. The former leads to formal certification, while the latter do not. Unfortunately, it is not possible to distinguish in the data general training (which increases the productivity of people working for any employer) from specific training (which 
increases the productivity of the workers but only while working for the employer that provided the training). Therefore, we interpret our measure of training as a mix of general and specific training, yet without knowing the relative shares of each one of them.

In Table 2, weighted means of a number of the key variables used in our analysis are presented separately for males and females and by SLID panel. The employer-supported

Table 2 Weighted sample characteristics in first year of each SLID panel by gender

\begin{tabular}{|c|c|c|c|c|}
\hline & \multicolumn{2}{|c|}{ Panel 4} & \multicolumn{2}{|c|}{ Panel 5} \\
\hline & Male & Female & Male & Female \\
\hline \multirow[t]{2}{*}{ Employer-supported Course Enrollment } & 0.299 & 0.269 & 0.276 & 0.244 \\
\hline & [2310] & {$[2277]$} & {$[2150]$} & [2089] \\
\hline \multirow[t]{2}{*}{ Employer-supported course enrolment intensity (in hours) } & 88.015 & 69.435 & 59.809 & 46.728 \\
\hline & {$[2278]$} & {$[2259]$} & {$[2110]$} & {$[2057]$} \\
\hline \multicolumn{5}{|l|}{ Education in first year of panel } \\
\hline \multirow[t]{2}{*}{ High School } & 0.162 & 0.175 & 0.152 & 0.164 \\
\hline & [1072] & [1234] & {$[1065]$} & [1220] \\
\hline \multirow[t]{2}{*}{ Post-Secondary (no certificate) } & 0.128 & 0.119 & 0.130 & 0.126 \\
\hline & [762] & [781] & {$[767]$} & {$[825]$} \\
\hline \multirow[t]{2}{*}{ Post-Secondary (with certificate) } & 0.350 & 0.367 & 0.370 & 0.374 \\
\hline & [2315] & {$[2761]$} & {$[2361]$} & {$[2706]$} \\
\hline \multirow[t]{2}{*}{ Bachelor degree (only) } & 0.136 & 0.153 & 0.137 & 0.162 \\
\hline & [723] & [968] & {$[737]$} & [1037] \\
\hline \multirow[t]{2}{*}{ Above Bachelor degree } & 0.076 & 0.054 & 0.076 & 0.057 \\
\hline & {$[394]$} & {$[316]$} & {$[370]$} & [348] \\
\hline \multicolumn{5}{|l|}{ Job characteristics: } \\
\hline \multirow[t]{3}{*}{ Hourly wage rate } & 22.549 & 17.634 & 21.869 & 17.286 \\
\hline & $(11.627)$ & (9.324) & $(11.828)$ & $(9.545)$ \\
\hline & [4931] & {$[5087]$} & [4993] & {$[5247]$} \\
\hline \multirow[t]{2}{*}{ Tenure of job (in months) } & 136.080 & 113.800 & 134.481 & 111.671 \\
\hline & [6409] & [6532] & [6398] & {$[6502]$} \\
\hline \multicolumn{5}{|l|}{ Demographics } \\
\hline \multirow[t]{2}{*}{ Age } & 40.700 & 40.814 & 40.492 & 40.403 \\
\hline & [7030] & [7623] & [6968] & {$[7474]$} \\
\hline \multirow[t]{2}{*}{ Visible Minority } & 0.142 & 0.147 & 0.161 & 0.170 \\
\hline & [497] & [561] & {$[594]$} & [669] \\
\hline \multirow[t]{2}{*}{ Immigrant } & 0.207 & 0.222 & 0.198 & 0.216 \\
\hline & [791] & [934] & [833] & {$[955]$} \\
\hline \multirow[t]{2}{*}{ Recent immigrant ( $<10$ years) } & 0.063 & 0.066 & 0.056 & 0.074 \\
\hline & [216] & [258] & {$[225]$} & {$[299]$} \\
\hline \multirow[t]{2}{*}{ Recent immigrant ( $<5$ years) } & 0.033 & 0.039 & 0.033 & 0.042 \\
\hline & [119] & [149] & {$[131]$} & [167] \\
\hline \multirow[t]{2}{*}{ Married } & 0.601 & 0.609 & 0.555 & 0.588 \\
\hline & {$[4471]$} & {$[4890]$} & {$[4148]$} & [4601] \\
\hline Total Observations & 7030 & 7623 & 6968 & 7474 \\
\hline
\end{tabular}

Note:

1. Weighted sub-sample size for each characteristic is presented in square brackets. The sample mean is calculated by applying weights, but the sample size is the one without weights.

2. The statistical summaries are restricted to the population aged from 25 to 55 years old. 
course enrollment variable equals one if the respondent reported being enrolled in a course with the support of his/her employer in any of the years of the panel ${ }^{5}$. The proportion of men reporting this is 29.9 percent in panel 4 and 27.6 percent in panel 5. For women, the proportion is 26.9 percent in panel 4 and 24.4 percent in panel 5 . In the second row, we provide the mean hours spent in employer supported course enrollment over the panel time period. Each survey year of each of the two SLID panels includes a question on hours spent in course enrollment that year. Unfortunately, the question does not distinguish between time spent in course enrollment with and without employer support. Our approach to approximating the total time spent in employer supported course enrollment is to identify the years in which the respondent identified employer supported course enrollment and then aggregate the total hours spent in it over those years. This will be an upwardly biased estimate of the total hours spent in employer supported course enrollment since some respondents may do both: 1) course enrollment without employer support, and 2) course enrollment with employer support, in the same year. For men, mean hours in employer supported course enrollment is 88.0 in panel 4 and 59.8 in panel 5. For women, the equivalent figures are 69.4 and 46.7. Therefore, while the incidence of employer supported course enrollment is only three percentage points higher for men, the average number of hours spent in this form of adult education is 13-19 hours higher for men relative to women across the two panels.

In Table 2, we also report the breakdowns of the key variables by level of education of the respondent in the first year of each panel. The distributions for men and women follow the patterns that one would expect and are very similar across the two panels. In the bottom panel of the table, we present other key characteristics of our respondents based on how they are reported in the first year of each panel. As expected, hourly wage rates (deflated to 2008 dollars using the Consumer Price Index for Canada) are higher for men than for women in each panel as is the case for months of job tenure. The immigrant proportion of the sample is 20 to 22 percent, while the proportion of recent immigrants is 6 to 7 percent for those arriving in Canada in the previous 10 years and 3 to 4 percent for those arriving in the previous five years.

\section{Empirical framework: the matching approach}

There is a large literature on empirical methods for estimating causal parameters of interest under the assumption that one observes in the data relevant pre-treatment covariates that affect both the likelihood of training participation and the outcomes of interest. Among these methods that rely on the assumption of unconfoundedness or selection on observables, the matching approach has received considerable attention in this literature due to its empirical properties and intuitive appeal (e.g., Heckman et al. 1997, Imbens 2014). In contrast to standard OLS methods that also relied on the selection on observables assumption, rather than assuming a functional form for the outcome equation, matching computes directly the counterfactual outcome by comparing trained and untrained individuals that are 'similar' in terms of pre-treatment characteristics. Relaxing the functional form assumption of the outcome equation is indeed a clear advantage for matching methods when nonlinearities are presented in the data under analysis. As a matter of fact, imposing a linear specification in the wage equation for measures of training intensity in our data shows to be problematic as inference 
about whether women training participants benefit more than men is quite dependent on the linear or quadratic specification of training on the parametric wage equation (see Additional file 1).

Let $Y_{1}$ and $Y_{0}$ be the potential wages for trainees conditional on participation and non-participation. Let $T \in\{0,1\}$ indicate training participation. For any individual, only one component of $T$ can be observed in the data. The data we observe for each unit is therefore $(Y, T, X)$, with $X$ representing a vector of pre-treatment covariates and $Y$ the observed wages. The identification of the counterfactual outcome is possible after invoking two key assumptions that together imply that one can estimate the average treatment effects by adjusting for differences in pre-treatment covariates between treated and untreated samples.

The first assumption, the unconfoundedness assumption, is defined as $T \bigsqcup Y_{0} \mid X$, which states that assignment to training is not confounded conditional on a set of pretreatment covariates, $X$. It rules out any systematic selection into levels of the treatment based on unobserved characteristics correlated with outcomes. Rosenbaum and Rubin (1983) show that if the unconfoundedness assumption holds for $X$ then it also holds for the conditional probability of participation or propensity score, $P(X)=\operatorname{Pr}(T=1 \mid X)$. Replacing $X$ with $P(X)$, the assumption becomes $T \bigsqcup Y_{0} \mid P(X)$. The propensity score will produce valid matches for estimating the impact of the employer's intervention on wages if relevant covariates correlated with training enrollment and wages are observable. This means including plausibly exogenous variables that are usually included in Mincerian wage models as well as variables that one expects to affect both participation in training and wages, but which one thinks are correlated with the error term in the wage equation (endogenous covariates). A case in point is the inclusion of variables such as occupation, tenure, or job status that are usually considered 'endogenous' in the context of Mincerian wage OLS models but which are useful in the specification of the propensity scores model. As discussed in the previous section, the SLID dataset provides rich and relevant information for both types of variables as we observe in the data variables including education, age, gender, marital status, ethnicity, immigration status, tenured status, firm size, occupation, and province of residence. They are jointly considered a relevant set of variables in any published study about training in the Canadian labor market (e.g., Dostie 2013, Turcotte and Rennison 2004).

Matching methods force us to compare comparable individuals by relying on the common support assumption $\operatorname{Pr}(T=1 \mid X)<1$ for all of $X$. This second assumption ensures that for each $X$ satisfying the conditional independence assumption there is a positive probability of finding a match for each treatment individual. Otherwise, if there were $X$ for which everyone received treatment, then it would not be possible for matching to construct the counterfactual outcomes for these individuals. By relying on an empirical common support, matching methods show a potential advantage with respect to standard OLS models. If the covariate distributions differ substantially between treated and control groups, OLS point estimates can be very sensitive to minor changes in the specification of the model because of their heavy reliance on extrapolation. In contrast, by using observations in the treatment and comparison groups over the region of common support, and by reweighting the comparison group observations, one lessens concerns about the "comparability" of the treatment and comparison groups. Our confidential data includes information for more than 3,000 workers from which we are confident to draw comparable treated and untreated units. 
The combination of these two assumptions is referred in the literature as 'strong ignorability' (Rosenbaum and Rubin 1983). Importantly, while examining the distribution of the covariates between the treatment and control groups can be done easily, assessing the plausibility of the unconfoundedness assumption is difficult to do. In this perspective, we acknowledge that the inclusion of covariates related to innate ability and non-cognitive skills such as motivation and ambition in the specification of the propensity score might have the power to reduce selection issues in training decisions with observational data. Unfortunately, these types of personal trait variables are not available in the SLID data. Therefore, to remove the effects of time-invariant unobserved characteristics that potentially affect both training participation and wages, we exploit the longitudinal structure of the SLID data by implementing difference-indifferences matching estimators (Heckman et al. 1998). This estimator can be thought of as a conditional semiparametric version of the widely used parametric approach in which training impacts are measured as before-after differences.

We estimate the average treatment impacts for trainees (ATT) by computing first the counterfactual outcome for each individual in the treatment group (who received support from their employers to enroll in courses) by using a weighted average of the outcomes in the comparison group (who do not enroll in courses with employer support), and then averaging these results over the treatment group sample,

$$
\Delta^{A T T}=\frac{1}{n_{1}} \sum_{i \in n_{1}}\left\{\left[y_{i t+j}-y_{i t}\right]-\left\{\sum_{k \in n_{0}} w\left(\rho_{i}-\rho_{k}\right)\left[y_{k t+j}-y_{k t}\right]\right\}\right\}
$$

where $n_{1}$ and $n_{0}$ are the sample of treatment and comparison group individuals, $\rho_{l}=$ $P_{l}(X)$ for $1=\{i, k\}$ is the conditional propensity score, and $w\left(\rho_{i}-\rho_{k}\right)$ is a kernel weighting function that depends on the (Euclidian) distance between the conditional propensity score for each individual $k$ in the comparison group and the conditional propensity score for each individual $i$ in the treatment group for which the counterfactual is being constructed.

Comparing differences-in-differences matching estimates to standard OLS wage growth models is useful to ensure one understands what is driving any difference between the estimates (Imbens 2014). OLS models that are also based on the assumption of selection on observables are fundamentally not robust to the substantial differences in the pre-treatment distribution of covariates between treatment and control groups with observational data when the linearity assumption of the outcome equation fails. The parametric OLS estimates are reported in a companion online appendix.

\section{Determinants of employer-supported training}

Table 3 reports the estimated logit marginal effects for the rich set of covariates included in the training participation model $^{6}$. Data employed in the estimation of Table 3 are drawn from Panel 4 (2002-2007) and Panel 5 (2005-2009) of SLID and are analyzed separately. The propensity score matching estimation is based on the characteristics of the sub-samples in the first wave of each panel. Each panel was balanced by requiring that observations on all variables were available for each year of the panel. Longitudinal weights were used in the estimation. In this part of our analysis, the unit of observation is the person-year, so the corresponding standard errors for the marginal 
Table 3 Marginal effects from logit estimation of employer supported course enrollment

\begin{tabular}{|c|c|c|c|c|}
\hline \multirow[t]{2}{*}{ COEFFICIENT } & \multicolumn{2}{|c|}{ Panel 4} & \multicolumn{2}{|c|}{ Panel 5} \\
\hline & Male & Female & Male & Female \\
\hline \multicolumn{5}{|l|}{ Socio-Demographic } \\
\hline Age & $-0.0016^{* *}(0.0007)$ & $0.0002(0.0007)$ & $-0.0009(0.0007)$ & $-0.0006(0.0007)$ \\
\hline Tenure & $0.0006^{* * *}(0.00004)$ & $0.0008^{* * *}(0.0001)$ & $0.0007^{* * *}(0.0001)$ & $0.0007^{* * *}(0.0001)$ \\
\hline Tenure Squared & $-1.3 e-06^{* * *}(3 e-07)$ & $-1.6 e-06^{* * *}(4 e-07)$ & $-1.6 \mathrm{e}-06^{* * *}(3.9 \mathrm{e}-07)$ & $-1.4 \mathrm{e}-06^{* * *}(4 \mathrm{e}-07)$ \\
\hline Marital Status & $0.0286^{* * *}(0.011)$ & $-0.0092(0.009)$ & $0.037^{* * *}(0.012)$ & $-0.007(0.011)$ \\
\hline Visible minority & $-0.054^{* *}(0.025)$ & $-0.051^{*}(0.028)$ & $-0.046^{*}(0.025)$ & $-0.072^{* * *}(0.025)$ \\
\hline Immigrant & $-0.048^{* * *}(0.018)$ & $-0.033(0.022)$ & $-0.025(0.022)$ & $-0.055^{* *}(0.022)$ \\
\hline High school & $0.0467^{* *}(0.019)$ & $0.114^{* * *}(0.026)$ & $0.012(0.024)$ & $0.144^{* * *}(0.035)$ \\
\hline PSE & $0.092^{* * *}(0.0209)$ & $0.157^{* * *}(0.028)$ & $0.098^{* * *}(0.025)$ & $0.187^{* * *}(0.036)$ \\
\hline Certificate & $0.107^{* * *}(0.016)$ & $0.176^{* * *}(0.024)$ & $0.103^{* * *}(0.021)$ & $0.199^{* * *}(0.033)$ \\
\hline Bachelor & $0.1606^{* * *}(0.02)$ & $0.248^{* * *}(0.026)$ & $0.142^{* * *}(0.025)$ & $0.234^{* * *}(0.035)$ \\
\hline \multicolumn{5}{|l|}{ Geographic } \\
\hline PEl & $0.001(0.013)$ & $-0.011(0.012)$ & $0.009(0.015)$ & $0.003(0.014)$ \\
\hline Quebec & $-0.0372^{* * *}(0.014)$ & $-0.039^{* * *}(0.014)$ & $-0.026(0.016)$ & $-0.048^{* * *}(0.016)$ \\
\hline Manitoba and Saskatoon & $-0.0051(0.013)$ & $0.004(0.012)$ & $0.011(0.015)$ & $0.004(0.015)$ \\
\hline Alberta & $0.0368^{* * *}(0.014)$ & $0.043^{* * *}(0.015)$ & $0.0009(0.016)$ & $0.039^{* *}(0.016)$ \\
\hline$B C$ & $0.0061(0.016)$ & $-0.001(0.016)$ & $-0.001(0.016)$ & $-0.001(0.018)$ \\
\hline New Foundland & $-0.003(0.022)$ & $-0.074 * * *(0.021)$ & $-0.065^{* * *}(0.02)$ & $-0.026(0.025)$ \\
\hline \multicolumn{5}{|l|}{ Labor Market } \\
\hline Ind. Trade & $-0.0365^{* *}(0.0146)$ & $-0.0512^{* *}(0.023)$ & $-0.006(0.018)$ & $-0.081^{* * *}(0.025)$ \\
\hline Ind. Finance & $0.011(0.019)$ & $0.049 * *(0.024)$ & $0.045^{*}(0.025)$ & $0.020(0.024)$ \\
\hline Ind. Profess. & $0.008(0.018)$ & $0.023(0.021)$ & $0.020(0.02)$ & $0.043^{*}(0.023)$ \\
\hline Ind. Information & $-0.027(0.021)$ & $-0.0388(0.028)$ & $-0.056^{* *}(0.026)$ & $-0.014(0.028)$ \\
\hline Ind. Services & $0.035(0.026)$ & $0.0225(0.034)$ & $0.064^{* *}(0.028)$ & $0.025(0.035)$ \\
\hline Ind. Pub. Adm. & $0.101^{* * *}(0.018)$ & $0.088^{* * *}(0.025)$ & $0.114^{* * *}(0.021)$ & $0.104^{* * *}(0.026)$ \\
\hline Firm 20-99 w & $0.1098^{* * *}(0.016)$ & $0.063^{* * *}(0.015)$ & $0.101^{* * *}(0.018)$ & $0.048^{* * *}(0.018)$ \\
\hline Firm 100-49w & $0.137^{* * *}(0.0156)$ & $0.081^{* * *}(0.014)$ & $0.136^{* * *}(0.018)$ & $0.063^{* * *}(0.018)$ \\
\hline Firm 500-999w & $0.1553^{* * *}(0.0197)$ & $0.082^{* * *}(0.017)$ & $0.195^{* * *}(0.021)$ & $0.079^{* * *}(0.022)$ \\
\hline Firm $+1000 w$ & $0.1756^{* * *}(0.013)$ & $0.105^{* * *}(0.013)$ & $0.169^{* * *}(0.015)$ & $0.099^{* * *}(0.015)$ \\
\hline Business & $-0.045^{* *}(0.019)$ & $-0.109^{* * *}(0.019)$ & $-0.036(0.023)$ & $-0.083^{* * *}(0.019)$ \\
\hline Appl. sciences & $-0.019(0.018)$ & $-0.039(0.032)$ & $0.011(0.021)$ & $-0.097^{* * *}(0.031)$ \\
\hline Health & $0.048(0.037)$ & $0.0006(0.021)$ & $0.045(0.035)$ & $0.027(0.024)$ \\
\hline Social sciences & $-0.043(0.026)$ & $-0.013(0.021)$ & $-0.008(0.027)$ & $-0.004(0.023)$ \\
\hline Culture & $-0.117^{* * *}(0.04)$ & $-0.111^{* * *}(0.038)$ & $-0.091^{* *}(0.041)$ & $-0.105^{* * *}(0.036)$ \\
\hline Services & $-0.053^{* * *}(0.017)$ & $-0.097^{* * *}(0.020)$ & $-0.097^{* * *}(0.020)$ & $-0.101^{* * *}(0.022)$ \\
\hline Transportation & $-0.0902^{* * *}(0.016)$ & $-0.061^{*}(0.035)$ & $-0.051^{* *}(0.022)$ & $-0.124^{* * *}(0.044)$ \\
\hline Industry & $-0.0899^{* * *}(0.026)$ & $-0.176^{* * *}(0.051)$ & $0.009(0.027)$ & $-0.178^{* * *}(0.047)$ \\
\hline Manufacturing & $-0.131^{* * *}(0.022)$ & $-0.271^{* * *}(0.039)$ & $-0.11^{* * *}(0.029)$ & $-0.173^{* * *}(0.052)$ \\
\hline Observations & 4289 & 4441 & 4405 & 4530 \\
\hline
\end{tabular}

Note: Marginal effects from a logistic regression. Clustered person-year standard errors in parenthesis. ${ }^{* * *}$ statistically significant at $1 \%,{ }^{* *}$ statistically significant at $5 \%,{ }^{*}$ statistically significant at $10 \%$.

effects are clustered at the person-year level. We included a rich set of covariates that are deemed relevant in the literature of employer-sponsored adult training in Canada (e.g., Hui and Smith 2003). These pre-treatment variables include 'exogenous' covariates 
(education, age, marital status, household income, immigration status, race indicator, province of residence) as well as 'endogenous' variables (tenure, firm size, job status, occupation categories) that one commonly expects to be correlated with the error term in the wage equation. It is worth noting that the role of the propensity score model specification is not to maximize the predictive capability of the model but to balance the distribution of relevant pre-treatment covariates between treated and untreated individuals. Thus, selection of covariates has followed directly from the requirements (assumptions) inherent to the matching approach.

Effective evaluation of employer-supported training depends on understanding the process by which workers choose to participate or not. Therefore, before assessing the distribution and balancing properties of the estimated propensity scores, we analyze the sign and statistical significance of the marginal effects for some specific covariates included in the model. Consistent with the 'learning begets learning' hypothesis (Myers and Myles 2005), Table 3 shows that more educated workers are more likely to participate in employer-supported adult training relative to their less educated counterparts in Canada. This result holds for both men and women and across Panels 4 and 5. This is in line with the overall pattern emerging from studies for other countries that suggests that employer-sponsored training increases significantly with the level of formal schooling, which is consistent with the idea that existing human capital constitutes a valuable input to the production of new human capital (Lillard and Tan 1992). The estimated marginal effects are sizable in magnitude, reaching up to 25 percentage points for college graduates relative to workers with less than high school. Moreover, the marginal effects are almost twice as large for women relative to men.

While human capital theory predicts a negative relation between age and participation in training programs as the discounted expected benefits from training lower with age, we do not find statistically significant marginal effects for age - with the exception of the case of men in Panel 4, where a negative relationship is found. One explanation to this intriguing result is that we use age and tenure in the same specification. Theory predicts that if existing human capital is a complement to further investments in training, then workers with more experience or tenure should undertake more training (Hui and Smith 2003). Therefore, tenure effects might mask the age effects on the likelihood of participation as tenure and age are positively correlated. Table 3 shows the marginal effects for the job tenure variable which are statistically significant for both men and women in Panels 4 and 5, although the magnitudes of the effects are small.

Credit constraints are usually considered important for training decisions as they have the power to restrict workers from borrowing against the future returns from human capital investments. Following the literature, we use marital status as proxies for credit constraints in the specification of the propensity score model. Table 3 reports positive and statistically significant marginal effects for married men in both Panels 4 and 5. For women, on the other hand, we observe no statistically significant results.

Standard Human Capital models also consider dimensions such as language skills and discrimination as relevant determinants of wages and employment. We use race and immigration status as proxies for these dimensions. Consistent with previous findings in this literature, Table 3 shows that participation in employer-supported course enrollment is lower for visible minority workers (relative to the Canadian born, non-visible minority reference group) and for immigrants; although the result for 
immigrants is not present in all cases as one observes not statistically significant marginal effects for males in panel 5 and for women in panel 4.

Finally, the richness of our participation model is enhanced by the inclusion of a set of indicators for geographic location that control for differences in local market conditions as well as several occupational categories and firm size indicators that control for workspecific characteristics. Consistent with previous findings in Canada and the U.S., we find that the probability of employer-supported training increases almost monotonically with the size of the firm.

A key question to assess is whether the distribution of the estimated propensity scores for the treated and untreated samples yields a large overlapping support in the data. Lack of support will be a direct violation of the second assumption of the matching approach. Figure 1 shows the distribution of the estimated propensity scores for men and women (pooled sample) in Panels 4 and 5. We find no support issues in the SLID data for the estimated probability of employer-supported training participation for both men and women. Minor support problems arise for very high values of the estimated propensity scores, but given that the fraction of treatment units in those regions are quite small, the lack of support is marginal and will not affect the relevance of the method. This assessment does not change when we repeat the same analysis separately for men and women.

Next, we consider the normalized differences in average covariates to assess whether the treatment and control groups observed characteristics are indeed balanced conditional on the estimated propensity score. Large values for the normalized differences will affect the plausibility of the unconfoundedness assumption in the SLID data. Table 4 presents the results for Panels 4 and 5 of the SLID data. We focus our attention on the mean (and median) absolute standardized bias, a summary statistic that shows whether the propensity score matching specification is successful in reducing bias for observational data ${ }^{7}$. The mean (median) bias is estimated over the total number of covariates used in the estimation of the propensity score specification. A value of ten or

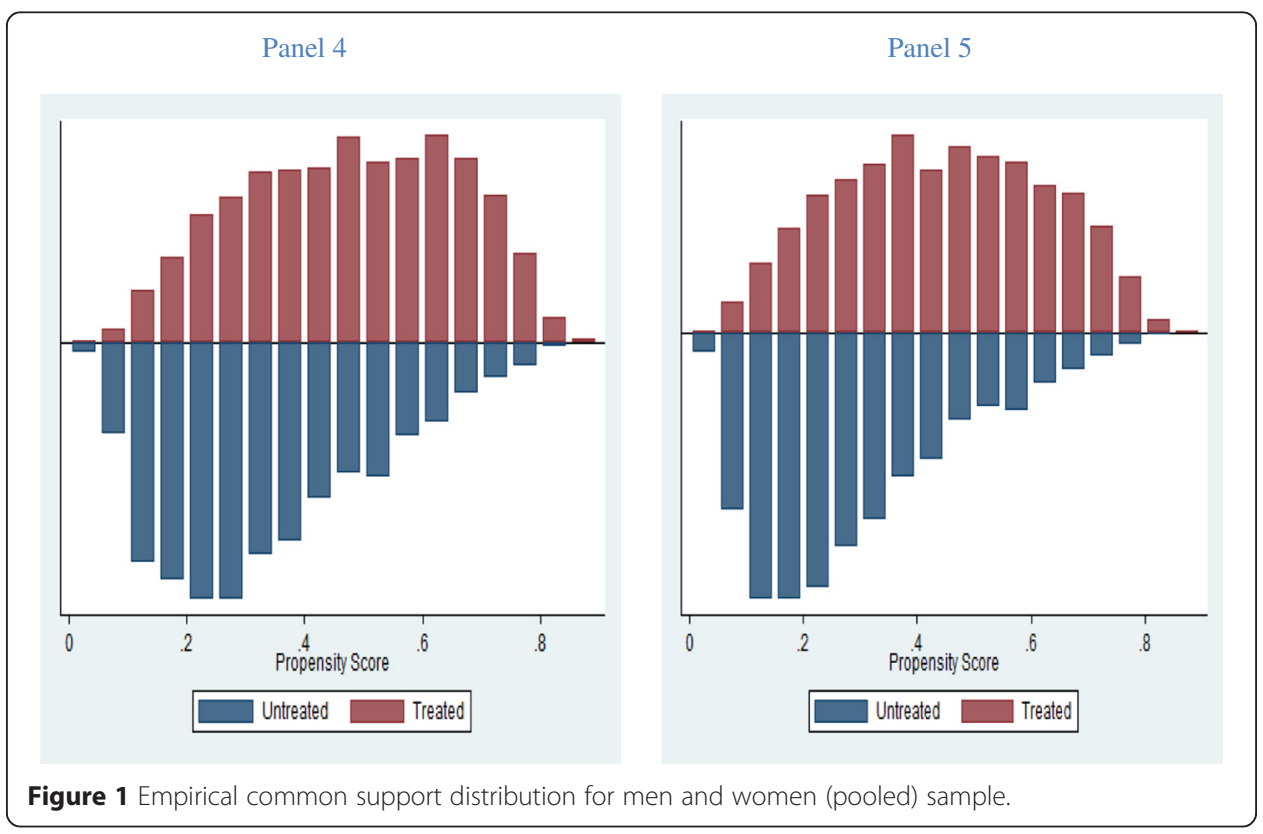


Table 4 Balancing test for pre-treatment covariates conditional on the propensity scores

\begin{tabular}{|c|c|c|c|c|c|c|}
\hline & \multicolumn{3}{|c|}{ Panel 4} & \multicolumn{3}{|c|}{ Panel 5} \\
\hline & Mean & Median & p-value- & Mean & Median & p-value- \\
\hline & Bias & Bias & chi2 & Bias & Bias & chi2 \\
\hline \multicolumn{7}{|l|}{ Men } \\
\hline unmatched & 12.5 & 11.2 & 0.00 & 13.6 & 9.6 & 0.00 \\
\hline \multicolumn{7}{|l|}{ Men } \\
\hline matched & 3.5 & 4.5 & 0.00 & 5.4 & 4.7 & 0.00 \\
\hline \multicolumn{7}{|l|}{ Women } \\
\hline unmatched & 17.0 & 10.6 & 0.00 & 17.0 & 11.6 & 0.00 \\
\hline \multicolumn{7}{|l|}{ Women } \\
\hline matched & 4.1 & 3.1 & 0.00 & 5.4 & 3.5 & 0.00 \\
\hline
\end{tabular}

Note: Mean Bias (median bias) refers to the mean (median) absolute bias across all covariates used in the specification of the propensity scores. For each covariate it is defined as the 'standardized' bias defined as the difference of the sample means in the treated and untreated samples as a percentage of the square root of the average of the sample variances in the treated and untreated groups. P-value-chi2 is the p-value of the likelihood-ratio test of the joint insignificance of all the regressors before and after matching.

lower is commonly invoked in the literature as an indication of covariate balance between treated and untreated samples (Rosenbaum and Rubin, 1985). For both men and women and across Panels 4 and 5, we observe low values for the mean and median absolute bias. They range from 3.5 to 5.4 for men and from 3.1 to 5.4 for women after conditioning on the propensity scores. In sum, Figure 1 and Table 4 give us confidence in the application of matching methods for employer-supported training in the context of the SLID data.

\section{Analysis of results}

Our main measure of the human capital investment variable is the incidence of training, which is an indicator variable that equals one if the respondent reported taking an employer-supported course in any of the panel years. We follow the regular practice of estimating the impacts of training for men and women separately due to differences in the dynamic process of training participation over the lifecycle labor supply. For each subsample, we estimated both cross-sectional and difference-in-differences kernel matching as the existing applied literature raises concerns about the sensitivity of the estimated impacts to econometric details (e.g., Smith and Todd 2005, Galdo et al. 2008) ${ }^{8}$. A large difference in the point estimates between both estimators would highlight that timeinvariant unobservables such as motivation, ambition, and ability play important roles in the training decisions. In all cases, the point estimates are presented along with their corresponding bootstrapped standard errors. An empirical common support is imposed over the estimation sample following the 'minimum of the maxima and the maximum of the minima' principle (Dehejia and Wahba 2002). It should be noted that our approach to measuring the returns from these mid-career investments in human capital focuses on the wage benefits from the investments and not the costs of these investments. Due to a lack of information, we do not incorporate the costs of the human capital investments (e.g., tuition costs), so we are not measuring a true return to the human capital investments.

\subsection{Incidence of training}

Table 5 reports the average treatment effect on the treated (ATT) estimates for men and women across panels 4 and $5^{9}$. For all subsamples, one observes that enrollment in 
Table 5 Average treatment effect on the treated-kernel matching estimates

\begin{tabular}{|c|c|c|c|c|c|}
\hline \multirow[b]{2}{*}{ Matching Method } & \multirow[b]{2}{*}{ Treatment Result } & \multicolumn{2}{|c|}{ Panel 4} & \multicolumn{2}{|c|}{ Panel 5} \\
\hline & & Male & Female & Male & Female \\
\hline \multicolumn{6}{|c|}{ D-in-D with common support } \\
\hline \multirow[t]{2}{*}{ Kernel } & ATT & $0.055^{* * *}$ & $0.088^{* * *}$ & $0.072^{* * *}$ & $0.071^{* * *}$ \\
\hline & Std. error & 0.015 & 0.017 & 0.020 & 0.015 \\
\hline \multicolumn{6}{|c|}{ D-in-D w/o common support } \\
\hline \multirow[t]{2}{*}{ Kernel } & ATT & $0.055^{* * *}$ & $0.088^{* * *}$ & $0.072^{* * *}$ & $0.0702^{* * *}$ \\
\hline & Std. error & 0.017 & 0.014 & 0.017 & 0.018 \\
\hline \multicolumn{6}{|c|}{ Cross-sectional with common support } \\
\hline \multirow[t]{2}{*}{ Kernel } & ATT & $0.052^{* *}$ & $0.114^{* * *}$ & $0.110^{* * *}$ & $0.087^{* * *}$ \\
\hline & Std. error & 0.022 & 0.018 & 0.024 & 0.018 \\
\hline \multicolumn{6}{|c|}{ Cross-sectional w/o common support } \\
\hline \multirow[t]{2}{*}{ Kernel } & ATT & $0.051^{* *}$ & $0.111^{* * *}$ & $0.109^{* * *}$ & $0.084^{* * *}$ \\
\hline & Std. error & 0.021 & 0.021 & 0.020 & 0.019 \\
\hline Observations & & 2963 & 3071 & 2915 & 2944 \\
\hline
\end{tabular}

Notes: Propensity scores matching estimation based with Epanechnikov kernel weighting function with bootstrapped standard errors. Individuals in Panel 4 are tracked from 2002 to 2006, while individuals in Panel 5 are followed from 2005 to 2009 . ${ }^{* * *}$ statistically significant at $1 \%,{ }^{* *}$ statistically significant at $5 \%$.

employer-supported training over the panel period is associated with higher wage growth over the panel period than is the case for not participating in employersupported training. The difference-in-difference point estimates range in size from 5.5 to 8.8 percent in Panel 4 and from 7.1 to 7.2 percent in Panel 5 and are statistically significant at the 1 percent level, which indicates robust support for the idea that employer supported courses lead to higher wage growth for both men and women in Canada. The magnitude and statistical significance of the treatment estimates holds independently of whether we impose an empirical common support on the estimation sample or whether alternative values for the bandwidth parameter are selected. Our findings concur with the overall pattern found in both Canada and the U.S. for employer-sponsored training programs. Indeed, the size of the point estimates lie somewhat in the middle and lower range of previous estimates for Canada and the U.S., estimates that range between 1 and 17 percent in the former (see Table 1) and between 16 and 26 percent in the latter (e.g., Lillard and Tan 1992, Barron et al. 1997, Carneiro and Heckman 2003).

When assessing closely the difference-in-differences gender differences in the returns to employer-supported training, we generally observe that women benefit more than men as the former show wage premiums in the range of 7.1 to 8.8 percent, while the latter have wage premiums in the 5.5 to 7.3 percent range. This result diverges from previous studies that rely on Canadian data. Zhang and Palameta (2006) and Drewes (2008), the other two studies that use the same SLID survey, show either zero impacts for women or positive but smaller impacts relative to men. One possible explanation for this difference is the fact that, unlike Zhang and Palameta (2006) and Drewes (2008), our analysis is based on more up-to-date information as it uses the confidential versions of the 2002-2007 and 2005-2009 SLID panels rather than the 1998-2002 or 2002-2004 panels, respectively. Indeed, there are several reports that indicate gains in education and labor market outcomes for women in the last decade or so, which 
could be also affecting the returns to investments in adult education and training by gender. However, this assessment should be tempered as Table 5 shows that for some specifications, we do not find significant differences in the point estimates between women and men, particularly in Panel 5 of the SLID data. All in all, and from a statistical standpoint, women show equal or slightly higher returns to employer-sponsored training than men across our preferred difference-in-difference specifications.

Table 5 also reports results for cross-sectional matching that, instead of focusing on the change in the log wages, uses the log wage of the respondents in the final wave of each panel as the dependent variable ${ }^{12}$. Comparing cross-sectional matching impacts to difference-in-differences ones shed lights on the role of time-invariant unobserved factors in training decisions. For women, the cross-sectional ATT estimates are larger (than the log wage change estimates) for both panels 4 and 5 , with the point estimates at 11.4 and 8.7 percent, respectively. This may indicate positive selection as more motivated or able workers are more prone to take part in training activities. The smaller impacts observed for the difference-in-differences matching approach simply reveal that once we control for time-invariant unobserved workers' characteristics, training wage premiums decrease. For men, we observe the same pattern for Panel 5 in which the cross-sectional estimates increases to 11 percent. For panel 4, on the other hand, we observe no differences between cross-sectional and difference-in-difference approaches.

How do these matching estimates fare relative to parametric wage growth models? The companion online appendix shows the corresponding results for parametric wage growth specification models. Before discussing these results, it is important to note that in the specification of the parametric models, we do not use the same set of covariates included in the propensity score model since some regressors included in the propensity score specification are correlated with the error tern of the wage equation. While keeping that in mind, we find that difference-in-difference parametric models yielded somewhat higher point estimates with respect to their counterpart matching approach, particularly for men. The parametric estimates reported in Additional file 1: Table A1 of the online appendix range between 6.8 and 7.7 percent for men and from 9.3 to 7.4 for women. This overall result is in line with international evidence that shows that standard OLS returns to adult training are generally biased upward (see for instance, Heckman et al. 1999).

From a policy standpoint, it is important to know whether low-skilled individuals are benefiting less (or more) than high-skilled individuals. After all, the analysis of the determinants of participation in employer-supported programs reveals that the latter have much higher rates of participation than that of the former. On average, the rate of participation for women with a college degree, for instance, is 25 percentage points higher than for women with less than high school. Therefore, we focus on workers with relatively less formal education and consider whether the impact of employer supported course enrollment differs for these less educated workers relative to all other workers. In doing this, we consider two alternative definitions of less-skilled workers: (1) those with a high school diploma or less and (2) those who do not have a bachelor degree. The former imposes a strong restriction over the estimation sample as a small sample of individuals in our data lie in this particular category. Row 1 in Table 6 show the point estimates for the most restrictive definition of low-skilled workers. In the case of Panel 5, the point estimates are positive and statistically significant for both men (15.4 
Table 6 Difference-in-differences average treatment effect by type of worker

\begin{tabular}{|c|c|c|c|c|c|}
\hline \multirow[b]{2}{*}{ Matching Method } & \multirow[b]{2}{*}{ Treatment Result } & \multicolumn{2}{|c|}{ Panel 4} & \multicolumn{2}{|c|}{ Panel 5} \\
\hline & & Male & Female & Male & Female \\
\hline \multicolumn{6}{|c|}{ Less than high-school workers } \\
\hline & ATT & 0.050 & $0.068^{* *}$ & $0.154^{* * *}$ & $0.075^{* * *}$ \\
\hline & Std. error & 0.034 & 0.033 & 0.042 & 0.028 \\
\hline & $\mathrm{N}$ & 858 & 756 & 804 & 690 \\
\hline \multicolumn{6}{|c|}{ Less than bachelor degree } \\
\hline & ATT & $0.038^{* *}$ & $0.073^{* * *}$ & $0.116^{* * *}$ & $0.077^{* * *}$ \\
\hline & Std. error & 0.0174 & 0.016 & 0.021 & 0.017 \\
\hline & $\mathrm{N}$ & 2369 & 2382 & 2315 & 2238 \\
\hline \multicolumn{6}{|c|}{ Bachelor degree or more } \\
\hline & ATT & 0.122 & $0.063^{*}$ & 0.016 & -0.004 \\
\hline & Std. error & 0.037 & 0.035 & 0.048 & 0.038 \\
\hline & $\mathrm{N}$ & 594 & 689 & 600 & 706 \\
\hline
\end{tabular}

Notes: Propensity scores matching estimation based with Epanechnikov kernel weighting function with bootstrapped standard errors. Individuals in Panel 4 are tracked from 2002 to 2006, while individuals in Panel 5 are followed from 2005 to 2009 . ${ }^{* *}$ statistically significant at $1 \%,{ }^{* *}$ statistically significant at $5 \%,{ }^{*}$ statistically significant at $10 \%$.

percent) and women (7.5 percent), indicating higher wage growth for low-skilled workers who participated in employer supported course enrollment relative to those who did not. The corresponding estimates from Panel 4 are smaller in magnitude, particularly for men, who show positive but not statistically significant results. Women, on the other hand, show positive and statistically significant impacts of 6.8 percent.

Row 2 in Table 6 shows the point estimates for our second and preferred definition of low-skill workers as the estimation sample is based on a larger sample of individuals with education below the university degree level. Both men and women present positive and statistically significant effects ranging in size from 3.8 to 11.6 percent for men and 7.3 to 7.7 percent for women. Finally, in row 3, we repeat the same analysis for the subsample of high-skilled workers, those with a bachelor degree or more. Our analysis of high-skilled workers suggests that the impact on wage growth of employer supported course training differ substantively from that of the low-skilled workforce. The magnitude of the point estimates is negligible and lacks statistical significance in the case of panel 5 , while the corresponding results for panel 4 are positive but not statistically significant. The only exception is women in panel 4 who show statistically significant results but only at the 10 percent level. Overall, we find evidence that suggests that lowskilled workers benefit more from employer support training relative to high-skilled workers. This result is in line with the overall pattern emerging from studies in Canada and abroad that suggests that the least educated are less likely to participate in life-long formal learning, but when they do participate, they receive higher economic returns than do more educated workers (e.g., Blundell et al. 1999, Myers and Myles 2005).

\subsection{Intensity of training}

Assessing wage returns to intensity of training, rather than incidence of training, provides additional insights into the effectiveness of employer-sponsored adult training in Canada. We measure intensity of training as the total number of hours spent in course 
enrollment in each of the panel years. As the intensity of training measure is a continuous variable, we implement generalized propensity scores (GPS) with continuous treatments (Hirano and Imbens 2004) to estimate dose-response functions on wage growth. The GPS is defined as the conditional probability of receiving a particular level of treatment ' $t$ ' (hours of training) conditional on the same set of baseline covariates $X$ used in section 6.1. Identification of causal effects follows after invoking the standard unconfoundedness assumption used in the binary-treatment case, but this time, it is weakly defined at the 'local' treatment level of interest ' $t$ '. Applications of the GPS approach in the context of training programs can be found in Kluve et al. (2012) and Galdo and Chong (2012).

We follow the empirical approach outlined in Hirano and Imbens (2004) and use a normal distribution for the treatment given $X, T_{i} \mid X \sim N\left(\beta_{o}+\beta_{1}{ }^{2} X_{i}, \sigma^{2}\right)$, where $T$ is the level of treatment and $X$ is the same rich set of pre-treatment covariates we used in the standard binary-treatment case. For any individual, only one component of $T$, i.e., ' $t$,' can be observed in the data. Therefore, the estimated GPS is calculated as $\hat{G}_{i}=\frac{1}{\sqrt{2 \pi \hat{\sigma}^{2}}}$ $\exp \left(-\frac{1}{2 \hat{\sigma}^{2}}\left(T_{i}-\hat{\beta}_{0}-\hat{\beta}_{1}{ }^{\prime} X_{i}\right)^{2}\right)$, where $\left[\hat{\beta}_{0}, \hat{\beta}_{1}, \hat{\sigma}^{2}\right]$ are estimated by OLS methods. Next, we estimate the conditional expectation of wage growth by using a flexible regression function:

$$
E\left(\Delta Y_{i} \mid T_{i}, G_{i}\right)=\beta_{0}+\beta_{1} T_{i}+\beta_{2} T_{i}^{2}+\beta_{3} G_{i}+\beta_{4} G_{i}^{2}+\beta_{5} T_{i} \times G_{i}
$$

Finally, the parameter of interest, the dose-response function, $\beta(t)$, is estimated as the average of the estimated conditional expectation, $E\left(\Delta Y_{i} \mid T_{i}, G_{i}\right)$, evaluated over the distribution of ' $t$ ', $\hat{\beta}(t)=\frac{1}{n} \sum_{i=1}^{n}\left[\hat{\beta}_{0}+\hat{\beta}_{1} t_{i}+\hat{\beta}_{2} t_{i}^{2}+\hat{\beta}_{3} G_{i}+\hat{\beta}_{4} G_{i}^{2}+\hat{\beta}_{5} t_{i} \times G_{i}\right]$, where ' $t$ ' takes different percentiles corresponding to the sample distribution of the number of hours of training.

Results are presented in Figure 2. For both men and women we observe positive and monotonic increases in wage premiums along the number of hours spent in training. The estimated dose-response function ranges from 4 to 23 percent, which corresponds

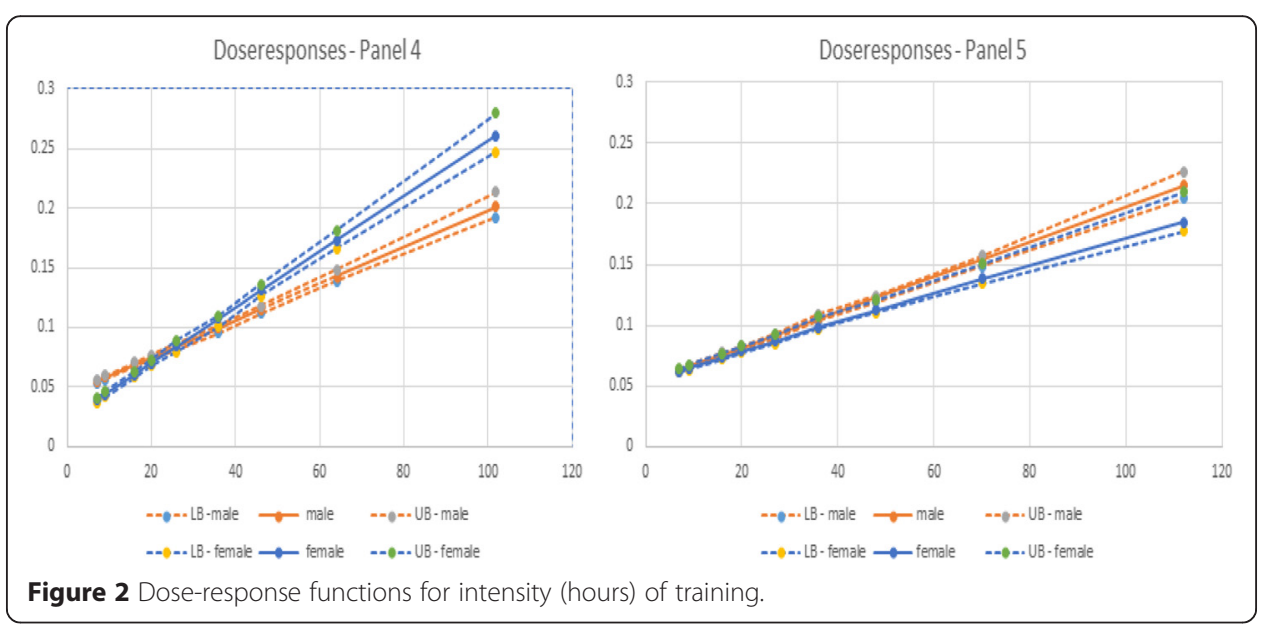


to individuals with 10 and 110 hours of training, respectively. In the middle range of training hours, between the fourth and sixth deciles, where statistically significant effects are reported and where most of the treated individuals are located, one observes a clear upward slope for wage premiums that ranges from 8 to 12 percent. This evidence suggests that, for men and women, the number of hours of employer-supported training matters.

Figure 2 also depicts a mixed picture with respect to gender gaps in wage premiums for our measure of training intensity. If we look at Panel 4, we observe that women have higher returns to training than that for men over most of the training-hour distribution. At the 70-90 hours range, which corresponds to the mean of training hours for that panel, we observe that women have significant higher returns to training than that for men, which amounts to a sizable difference of around 5 percentage points. By looking at Panel 5, on the other hand, we observe slightly higher wage premiums for men relative to women. At the 40-60 hours range, which corresponds to the mean of training hours for that panel, we observe slightly higher returns for men in the range of 1 to 2 percentage points above that of women.

It is important to mention that measuring intensity of training by self-reported accounts of number of hours might be prone to measurement error, which in turn might affect our estimated training impacts. In this regard, we assess our analysis of incidence of training in section 6.1 as more reliable and, thus, as our preferred set of results.

\section{Assessing the internal validity of the results}

In this section, we implement three alternative tests to assess threats to the internal validity of our results. First, we exploit the longitudinal nature of the SLID data to test whether a transitory wage drop is observed for individuals in the treatment group, as opposed to individuals in the control group, before training takes places. This is an effective way to assess whether the underlying 'parallel trends' assumption of differencein-difference methods holds in our data. Specifically, for workers who have taken the employer supported training in year 5 of the panel, one can compute mean wages in time $t-4, t-3, t-2, t-1, t, t+1$, where $t$ refers to the time of participation in employersupported training. For workers who have taken the employer supported training in year 4 of the panel, wage profiles for mean wages can be computed in time $t-3, t-2, t-1$, $t, t+1, t+2$, and so on. To make comparable the analysis between Panel 4 and Panel 5, and since evidence on Ashenfelter's Dip relies on the availability of data several periods before training takes place, we restrict the estimation sample to workers with three years of pre-treatment information, i.e., workers who took training in year 4 of the panel.

Figure 3 provides evidence against the Ashenfelter's Dip in our data. In fact, we do not observe any transitory drop in the mean earnings of the treated group in the previous three years before training takes place for both Panels 4 and 5. These figures also show that the pre-treatment wage profile for the untreated units show comparable levels and patterns with respect to the treated ones. This feature speaks loudly about the comparability of the two samples. After training takes place, we observe a clear upward shift in the mean wages profile only for the treated group, while the control group depicts a relatively flat profile. One possible explanation for the absence of transitory 


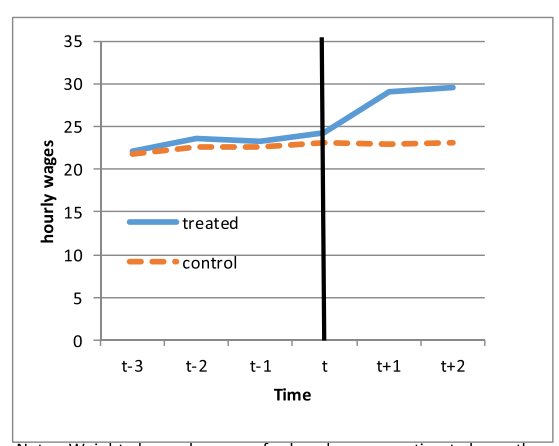

Notes: Weighted sample means for hourly wages estimated over the second longest wave 2002-2007 in Panel 5. Vertical line represents the training time ' $t$ '.

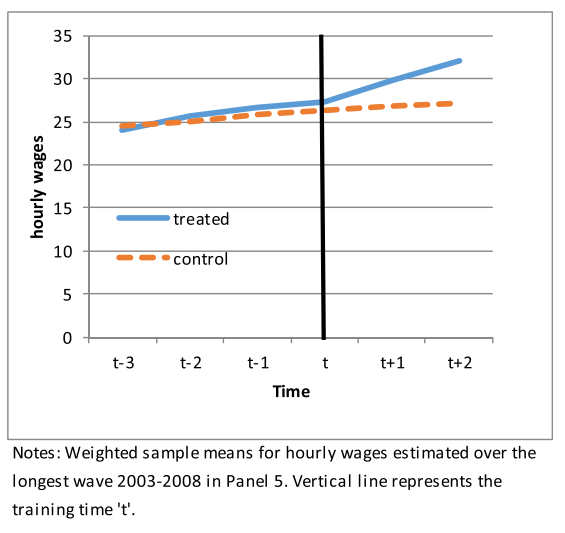

training time ' $\mathrm{t}$ '.

Figure 3 Hourly wage profile over time: treated versus untreated group individuals.

drops in wages for the treatment group is the fact that we are dealing with employersupported training rather than government-supported training participation. The latter usually serves (disadvantaged) individuals who experience layoffs or have labor market attachment problems prior to signing up for training. It is important to mention that these findings are not dependent on this estimation sample as we observe the same features when analyzing shorter pre-treatment time-span data, i.e., data for workers who took training in year 2 or 3 of the panel. In summary, the uncovered evidence suggests the plausibility of the underlying assumptions of the difference-in-differences estimator in the context of our data.

Next, we implement cross-sectional matching on the pre-treatment wage outcome. This test indirectly assesses the plausibility of the unconfoundedness assumption on the available dataset. If the estimated ATT on pre-treatment wages is negligible or statistically not significant, then one should interpret this evidence as an indication that the identification assumption of matching methods holds in the data at hand (Imbens 2014). Table 7 shows the estimated effects for men and women in Panels 4 and 5. A clear picture emerges: the estimated effects of employer sponsored training on the pretreatment wage variable are small and not statistically significant different from zero regardless of the participants' gender and the panel used in the estimation. This result is consistent with our findings in Figure 3 that showed similar (unconditional) mean wages for treatment and control groups in the pre-treatment periods.

Finally, we address the relevance of the available set of observed covariates included in the specification of the propensity score by implementing the Rosenbaum test (Rosenbaum 2002) to assess whether the estimates obtained using matching methods

Table 7 Cross-sectional kernel matching on pre-treatment outcome

\begin{tabular}{ccccccc}
\hline & & \multicolumn{2}{c}{ Panel 4 } & & \multicolumn{2}{c}{ Panel 5 } \\
\cline { 3 - 4 } Matching Method & Treatment Result & Male & Female & & Male & Female \\
\hline Kernel & ATT & 0.018 & 0.011 & & 0.022 & 0.011 \\
Observations & Std. error & 0.016 & 0.013 & & 0.015 & 0.013 \\
& & 4288 & 4436 & & 4402 & 4526 \\
\hline
\end{tabular}

Notes: Propensity scores matching estimation based with Epanechnikov kernel weighting function with bootstrapped standard errors. Individuals in Panel 4 are tracked from 2002 to 2006, while individuals in Panel 5 are followed from 2005 to 2009. 
are robust to the possible presence of hidden bias (unobserved confounder). Rosenbaum's method should be thought of as a sensitivity analysis that relies on the sensitivity parameter gamma $(\Gamma)$, which measures the degree of departure from the random assignment of treatment. Two individuals with the same observed covariates may differ in the odds ratio of program participation by at most a factor of $\Gamma$. This means that in a randomized control trial, random allocation ensures that $\Gamma$ is equal to 1 . In an observational study, on the other hand, if $\Gamma$ is equal to 2, and two subjects are identical on matched covariates, then one might be twice as likely as the other to receive the treatment because they differ in terms of an unobserved covariate.

In this part of the analysis, we ask how big the parameter $\Gamma$ needs to be in order to challenge the statistical significance of our findings. Table 8 presents the results for the difference-in-difference benchmark model. The critical levels of $\Gamma$ at which we would have to question our conclusion of statistically positive effects are 1.36 and 1.46 in panels 4 and 5 . That is, an unobserved covariate should increase the odds ratio of participating in employer-sponsored adult training by 36 and 46 percent, respectively, in order to challenge the statistical significance of our findings at the $10 \%$ level. It is important to highlight that these results represent a 'worse-case scenario' in the sense that the bounds assume a nearly perfect association between the unobservable and the outcome of interest. Using the effects of other predictors as a benchmark, the influence of an unobserved covariate to reverse our conclusion should be as strong as +10 years more of tenure, 9 more of age, and 12 percentage points less of high school only education. These differences seem difficult to revert. This result leads us to believe that the positive effects on earnings are unlikely to be driven by omitted variable bias.

Table 8 Rosenbaum bounds for test of unconfoundedness

\begin{tabular}{|c|c|c|c|c|c|c|}
\hline Gamma (Г) & sig+ & sig- & t-hat+ & t-hat- & $\mathrm{Cl}+$ & $\mathrm{Cl}-$ \\
\hline \multicolumn{7}{|c|}{ Diff-in-Diff model for Log Wage: Panel 4} \\
\hline 1 & 0 & 0 & 0.087013 & 0.087013 & 0.068185 & 0.105809 \\
\hline 1.1 & $1.80 \mathrm{E}-11$ & 0 & 0.064636 & 0.109332 & 0.0457 & 0.128248 \\
\hline 1.2 & 3.10E-06 & 0 & 0.044168 & 0.129788 & 0.025141 & 0.148683 \\
\hline 1.3 & 0.004783 & 0 & 0.025342 & 0.148488 & 0.006238 & 0.16737 \\
\hline 1.34 & 3.13E-02 & 0 & 0.018169 & 0.155517 & -0.00097 & 0.174479 \\
\hline 1.36 & 0.110433 & 0 & 0.01226 & 0.158212 & -0.007433 & 0.174479 \\
\hline \multicolumn{7}{|c|}{ Diff model for Log Wage: Panel 5} \\
\hline 1 & 0 & 0 & 0.09267 & 0.09267 & 0.074243 & 0.111161 \\
\hline 1.1 & $6.30 \mathrm{E}-14$ & 0 & 0.070572 & 0.114806 & 0.052146 & 0.133467 \\
\hline 1.2 & $6.10 \mathrm{E}-08$ & 0 & 0.050499 & 0.135114 & 0.031944 & 0.153673 \\
\hline 1.3 & 0.000405 & 0 & 0.031988 & 0.153632 & 0.013394 & 0.172309 \\
\hline 1.38 & 0.028381 & 0 & 0.018194 & 0.167513 & -0.00053 & 0.186268 \\
\hline 1.46 & 0.107181 & 0 & 0.011871 & 0.185605 & -0.006911 & -0.204624 \\
\hline \multicolumn{7}{|c|}{$\begin{array}{l}\text { Note: } \\
\text { 1. People in Panel } 4 \text { are tracked from } 2002 \text { to } 2006 \text { for five years, which is } \\
\text { are followed from } 2005 \text { to } 2009 \text { for five years. } \\
\text { 2. gamma - log odds of differential assignment due to unobserved factors } \\
\text { 3. sig-/+-lower and upper bound significance level. } \\
\text { 4. t-hat- }-+- \text { lower and upper bound Hodges-Lehmann point estimate. } \\
\text { 5. Cl-/+-lower and upper bound confidence interval }(a=.95) \text {. }\end{array}$} \\
\hline
\end{tabular}




\section{Conclusions}

While matching methods are common in the international literature, this paper is one of the few studies of its kind for Canada to use both longitudinal data and propensity score matching on the difference in wages before and after employer supported course enrollment. Propensity score matching was employed to account for potential biases due to selection into employer supported course enrollment related to the observable characteristics of the respondent. A relatively rich and relevant set of pre-treatment covariates included in the confidential versions of the Survey of Labour and Income Dynamics (SLID) of Statistics Canada were used in the specification of the propensity scores model. A variety of statistical tests were implemented satisfactorily to assess the internal validity of the estimates. We found no support issues in the SLID data for the estimated probability of employer-supported training participation for both men and women. We do not find evidence of an 'Ashenfelter's Dip' in our data in that there is no evidence of a transitory drop in the wages for the treatment group that would otherwise have put into question the validity of the underlying identification assumption of difference-in-difference methods.

Three main results emerge from this analysis. The average treatment effect on the treated estimates from the wage growth models show overall positive returns to employer-supported training programs. This positive result is observed at both the extensive and intensive margins of training. Relative to previous evidence for Canada and the U.S., our findings are in the middle to lower range of the point estimates distribution for adult training interventions. Moreover, women are benefiting to the same extent or somewhat more relative to men from participating in employer-supported adult training. Although the magnitude of the gender differences are somewhat sensitive to changes in the estimation sample and econometric details, results for women indicate equal or slightly higher returns to training relative to men among most specifications and sensitivity tests implemented. This result departs from previous evidence coming from studies that also used the Canadian SLID data in which sizable and statistically significant gender gaps in favor of men were found. One possible explanation for this difference is the fact that our analysis is based on more up-to-date information as it uses relatively recent versions of the SLID panels. Documented gains in the labor markets experienced by Canadian women in the past decade could have been also translating into higher returns to training. Indeed, more research in this area will be welcomed. Finally, even though high-skilled workers disproportionally signed up for employer-supported training relative to low-skilled ones, the former showed negligible and statistically insignificant training impacts, while the latter show sizable and statistically significant wage premiums. This result talks about the efficiency of the employerssupported training allocation by schooling levels. It might well be in the interest of firms to reallocate the share of training slots towards those located at the lower end of the schooling distribution.

\section{Endnotes}

${ }^{1}$ This rate of participation is still below the levels observed in United Kingdom (35 percent), the United States (45 percent), and several northern European countries (45 percent) (OECD 2003). 
${ }^{2}$ Research on the economic returns to formal education is extensive and well documented across countries and demographic groups (see Card 1999 for a survey). Canada has not been the exception, and particular research emphasis has been given to the study of returns to schooling. The consistent picture that emerges from Canadian data is the statistically significant returns to formal education in the marketplace. The estimates range between 3 and 15 percent depending on specific demographic groups. Women, for instance, are found to have consistently higher returns to formal education than are men (e.g., Beaudry and Green 1998, Card and Lemieux 2001).

${ }^{3}$ This literature has made an important distinction between participation in publicly sponsored training programs and lifelong learning education and training. The former targets particular groups of disadvantaged individuals and provides them a particular 'treatment' once eligibility conditions are satisfied. The latter is mostly job-related and the result of individuals' choices to update labor-market skills and competences. It can take the form of employer-sponsored training programs.

${ }^{4}$ The main explanatory variables used in making the weights are: ethnicity, country of origin, education level, marital status, size of area of residence, labor force status, class of worker, household income, owner, household size, family type (lone parent, couple, etc.), province, age group, and sex.

${ }^{5}$ The person is identified to be in employer-supported courses if he/she reports to participate in the employer-supported course in at least one of the years from 2003 to 2006 in panel 4, while the person in panel 5 needs have taken the course in at least one of the years from 2006 to 2008 .

${ }^{6}$ Fixed effect Logit estimation was also employed and resulted in insignificant estimates on most covariates due to relatively little variation in the explanatory variables over time.

${ }^{7}$ The standardized difference known as the 'standardized bias' is the difference of the sample means in the treated and untreated samples as a percentage of the square root of the average of the sample variances in the treated and untreated groups (Rosenbaum and Rubin, 1985). This statistic is considered more useful for assessing covariate unbalance between treated and untreated samples than the standard t-statistic for testing the null hypothesis that the two differences are zero (Imbens 2014).

${ }^{8}$ We report kernel based estimates which were generated by using the widely used Epanechnikov weighting function which depends on the distribution of the estimated propensity scores in the treated and untreated samples and a smoothing parameter $h$. The weighting function is $w^{\text {epan }}(i, j)=\left\{\begin{array}{l}1-\left|\frac{p_{i}-p_{j}}{h}\right|^{2} \text { if }\left|\frac{p_{i}-p_{j}}{h}\right|<1 \\ 0, \text { otherwise }\end{array}\right\}$, where $p_{i}$ and $p_{j}$ are the estimated propensity scores for individuals ' $i$ ' and ' $j$ ' in the treatment and untreated groups, and $u$ the smoothing parameter.

${ }^{9}$ Note that in order to compare the results across panels, we only use the data from the first five survey years of panel 4 since panel 5 has five years of longitudinal tracking. The estimation using the complete six survey years of panel 4 was also assessed without changing any of our conclusions.

\section{Additional file}

Additional file 1: Online appendix. 


\section{Competing interests}

The IZA Journal of Labor Policy is committed to the IZA Guiding Principles of Research Integrity. The authors declare that they have observed these principles.

\section{Authors' information}

WC is a Research Analyst at Statistics Canada. JG is an Associate Professor in the School of Public Policy and Administration and the Department of Economics at Carleton University, and a Research Fellow at the Institute for the Study of Labor (IZA), Bonn, Germany. MV is an Associate Professor in the Department of Economics at Carleton University. CW is a Professor in the Department of Economics at Carleton University and a Research Fellow at the Centre for Research and Analysis of Migration, London, UK. Authors' names appear in alphabetical order.

\section{Acknowledgements}

This project was funded as part of the SRDC-CLSRN project on adult education. We would like to thank Karen Myers, Craig Riddell, Arthur Sweetman, an anonymous referee and other participants in the project for helpful comments and suggestions. The authors retain full intellectual control over this paper and are free to submit it to any journal that they wish. The analysis presented in this paper was conducted at the COOL RDC which is part of the Canadian Research Data Centre Network (CRDCN). The services and activities provided by the COOL RDC are made possible by the financial or in-kind support of the SSHRC, the CIHR, the CFI, Statistics Canada, Carleton University, the University of Ottawa and the Université du Québec en Outaouais. The views expressed in this paper do not necessarily represent the CRDCN's or that of its partners'. Responsible editor: David Neumark

\section{Author details}

${ }^{1}$ Department of Economics, Carleton University, 1125 Colonel By Drive, Ottawa, ON K1S 5B6, Canada. ${ }^{2}$ School of Public Policy and Administration and Department of Economics, Carleton University, 1125 Colonel By Drive, Ottawa, ON K1S 5B6, Canada.

Received: 30 July 2014 Accepted: 7 April 2015

Published online: 15 May 2015

\section{References}

Almeida, R, \& Carneiro, P. (2009). The Return to firm Investments in Human Capital. Labour Econ, 16(1), 97-106. Barron, JM, Berger, MC, \& Black, DA. (1997). On-the-Job Training. Kalamazoo, Michigan: W.E. Upjohn Institute for Employment Research.

Beaudry, P \& Green, D. (1998). "What is driving US and Canadian wages: exogenous technical change or endogenous choice of technique?" NBER Working Paper No. 6853, December 1998.

Blundell, R, Dearden, L, Meghir, C, \& Sianesi, B. (1999). Human capital investment: The returns from education and training to the individual, the firm and the economy. Fisc Stud, 20, 1-23.

Card, D. (1999). "The Causal Effect of Education on Earnings." In Handbook of Labor Economics, Volume 3A. A. Ashenfelter and D. Card (eds.). New York: North Holland

Card, D, \& Lemieux, T. (2001). Can Falling Supply Explain the Rising Return to College for Younger Men? A Cohort-Based Analysis. Q J Econ, 116, 705-46.

Card, D, Kluve, J, \& Weber, A. (2010). Active Labour Market Policy Evaluation: A Meta-Analysis". Econ J, 120, F452-F477.

Carneiro, P \& Heckman, J (2003). "Human Capital Policy" NBER 9495.

Dehejia, R, \& Wahba, S. (2002). Propensity score matching methods for nonexperimental causal studies. Review of Economics and Statistics, 84(1), 151-161.

Dostie, B. (2013). Estimating the returns to firm-sponsored on-the-job and classroom training. J Hum Cap, 7(2), 161-189.

Dostie, B, \& Leger, PT. (2014). Firm-Sponsored Classroom Training: Is it Worth It for Older Workers? Canadian Public Policy, 40(4), 377-390.

Drewes, T. 2008. "Adult education and training from a longitudinal perspective", HRSDC.

Drolet, M. (2002). The Evolving Workplace Series: The "Who, What, When and Where of Gender Pay Differentials". Statistics Canada: WP, Catalogue 71-584-MIE \#4.

Frazis, H, \& Loewenstein, MA. (2005). Reexamining the returns to training: Functional form, magnitude, and interpretation. J Hum Resour, 40(2), 453-476.

Galdo, J, Smith, J, \& Black, D. (2008). Bandwidth selection and the estimation of treatment effects with unbalanced data. Annals of Economics and Statistics, 91-92, 189-216.

Galdo, J, \& Chong, A. (2012). Does the Quality of Public-Sponsored Training Programs Matter? Evidence from Bidding Processes Data. Labour Econ, 19(6), 970-986.

Havet, N. 2006. "La valorisation salariale et professionnelle de la formation en entreprise diffère-t-elle selon le sexe? L'exemple canadien", Working paper, Groupe d'Analyse et de Théorie Économique (GATE), UMR 5824 of the CNRS.

Heckman, J, Lalonde, R, \& Smith, J. (1999). "The Economics and Econometrics of Active Labor Market Programs", Chapter 31 in Orley Ashenfelter, David Card (eds.), Handbook of Labor Economics, Volume 3A, Elsevier Science, Amsterdam, North-Holland, p.1866-2097.

Heckman, J, Lochner, L, \& Taber, C. (1998). Tax Policy and Human-Capital Formation. Am Econ Rev Pap Proc, 88(May), 293-97.

Heckman, J, Ichimura, H, \& Todd, P. (1997). Matching as an Econometric Evaluation Estimator: Evidence from Evaluating a Job Training Programme. Review of Economics Studies, 64(4), 605-654.

Hirano, K, \& G Imbens. 2004. "The Propensity Score with Continuous Treatments", In A. Gelman \& X. Li eds., Applied Bayesian Modeling and Causal Inference from Incomplete-Data Perspectives. John Wiley and Sons.

Hui, S, \& Smith, J. (2001). "The labour market impacts of adult education and training inCanada". Ottawa: Statistics Canada Catalogue no. 81-595-MIE2003008. 
Hui, S-w, \& Smith, J. (2003). The Determinants of Participation in Adult Education and Training in Canada. Ottawa, Canada: Report Prepared for Human Resources and Development Canada.

Imbens, G. (2014) "Matching methods in practice: Three examples", IZA WP 8049

Kluve, J, Schneider, H, Uhlendorff, A, \& Zhao, Z. (2012). Evaluating Continuous Training Programs Using the Generalized Propensity Score. J R Stat Soc, Series A 175(2), 587-617.

Lillard L.A. \& Tan, H.W. 1992. "Private Sector Training: Who Gets it and What Are Its Effects?", Research in Labor Economics, Vol 13:1-62.

Myers, K. \& J. Myles. 2005. "Self-Assessed Returns to Adult Education Life-long Learning and the Educationally Disadvantaged", CPRN Research Report.

OECD. (2003). Beyond Rhetoric: Adult Learning Policies and Practices. Paris: OECD.

Parent, D. (2003). Employer-supported training in Canada and its impact on mobility and wages. Empir Econ, 28, 431-459. Rosenbaum, PR. (2002). Observational Studies (2nd ed.). New York: Springer.

Rosenbaum, P, \& Rubin, D. (1983). The Central Role of the Propensity Score in Observational Studies For Causal Effects. Biometrika, 70(1), 33-38.

Rosenbaum, P, \& Rubin, D. (1985). Constructing a Control Group using a Multivariate Matched Sampling Methods that Incorporate the Propensity Score. Am Stat, 39(1), 41-55.

Smith, J, \& Todd, P. (2005). Does Matching Overcome LaLonde's Critique of Non Experimental Estimators? J Econ, 125(1-2), 305-353.

Turcotte, J, \& Rennison, LW. (2004). The Link Between Technology Use, Human Capital, Productivity and Wages: Firm-Level Evidence. International Productivity Monitor, 9(Fall), 25-36.

Yoshida, Y, \& Smith, MR. (2005). Training and the Earnings of Immigrant Males: Evidence from the Canadian Workplace and Employee Survey. Soc Sci Q, 86(5), 1218-1241.

Zhang and Palameta (2006) "Participation in adult schooling and its earnings impact in Canada", Analytical Studies Branch Research Paper Series No. 276, Statistics Canada.

\section{Submit your manuscript to a SpringerOpen ${ }^{\circ}$ journal and benefit from:}

- Convenient online submission

- Rigorous peer review

- Immediate publication on acceptance

- Open access: articles freely available online

- High visibility within the field

- Retaining the copyright to your article

Submit your next manuscript at $\boldsymbol{\wedge}$ springeropen.com 